\title{
Study of the Efficiency of Ultrasonic Turning of Heat-Resistant Alloys with Tools from Mineral Ceramics
}

\author{
Nguyen Khanh Toan ${ }^{1 *}$, and Nikolay Mezin ${ }^{2}$ \\ ${ }^{1}$ Hanoi Polytechnic University, the Socialist Republic of Viet Nam, Hanoi \\ ${ }^{2}$ Ulyanovsk State Technical University, 432027, Ulyanovsk, 32 Severny Venets Street, the Russian \\ Federation
}

\begin{abstract}
The results of the study of the effectiveness of high-speed ultrasonic turning of billets from heat-resistant nickel alloys without coolant are given. It was established that the introduction of ultrasonic field energy into the shaping zone reduces the contact temperature by 10 $15 \%$ and the cutting force by $20-30 \%$. However, this does not cause a decrease in metal removal performance due to a significant loss of strength and ease of cutting at temperatures above $800 \mathrm{C}$. As follows from the results, ultrasound helps to reduce the thickness of the defective layer, the formation of which is caused by thermal processes and phase transformations with the appearance of tensile residual stresses in the surface layer.
\end{abstract}

\section{Introduction}

The wide distribution of heat-resistant alloys in such industries as the production of rocketspace and aviation technology makes it necessary to carry out an intensive search for new high-performance technologies for manufacturing parts from them. Traditional technologies for processing billets of heat-resistant alloys, classified as difficult-to-work, do not allow to achieve high values of the cutting mode elements (cutting speed, feed). This is due to their physico-mechanical properties, such as high hardening of the material in the process of deformation by cutting, the ability of the material to retain the original strength and hardness at high temperatures in the cutting zone, low thermal conductivity, contributing to insufficient heat removal from the contact zone of the tool and the workpiece, as well as the presence in their composition of inter metallic or carbide inclusions, leading to abrasive wear of the cutting edge of the tool.

The most effective processing of nickel-based heat-resistant alloys can be conducted with an instrument made of a material characterized by high cutting properties, such as high red hardness, stability of cutting properties over a wide temperature range and resistance to abrasive wear. The carbide tools currently used as tool materials do not sufficiently possess the required characteristics.

The low machinability of super alloys is determined by their physicomechanical

${ }^{*}$ Corresponding author: mr.toannk@gmail.com 
properties. Under these conditions, it is very necessary to disclose the causes affecting their workability, and to find ways and means of increasing the productivity of their processing on machine tools.

The basic structure of most high-temperature alloys is usually a solid solution of austenitic class with a face-centered cubic lattice. In this case, most of the deformable heatresistant alloys belong to the type of dispersion hardening, i.e. in these alloys, the structural component is separated from the solid solution - the second phase, which is different from its base and is dispersed throughout the entire volume of the alloy in finely divided form.

The high dispersion of the structure prevents the emergence and development of slip processes, and the creep resistance of the alloy increases.

High-strength nickel-based alloys are characterized by a significant loss of strength and ease of cutting at temperatures above 800 C. $[1,2,5,6]$. Considering that such temperatures on the surface layer of the work piece are associated with a high probability of occurrence of defects in the part being manufactured, this feature can probably be used at least for preliminary (roughing) processing. Therefore, it is important to choose the material of the cutting part of the tool, working in high-speed software processing on modern machining centers.

It is well known that the use of modern types of mineral ceramics as a tool material is characterized by the ability to retain its physicomechanical properties under conditions of sufficiently high temperatures at which even very difficult-to-process materials, in particular, nickel-based super alloys, soften [3]. In this regard, it is possible to significantly increase the cutting speed to values of $600-1000 \mathrm{~m} / \mathrm{min}$, which is not achievable when using tools made of hard alloy. At the same time, it should be borne in mind that mineral ceramics has a very low thermal conductivity, and therefore, the component of the heat balance of the cutting process attributable to the cutting tool (as in grinding) is very small. Therefore, the main part of the generated heat will intensively heat the surface layer of the workpiece and will not be able to go deep into it due to the poor thermal conductivity of such alloys. The use of mineral ceramics as a cutting part of the tool eliminates the use of coolant during processing, since its contact with the surface of the processing plates leads to thermal shock and their catastrophic destruction. Of particular scientific interest are the phase transformations of the surface layer of the workpiece, which is important for determining the minimum allowance for the final operations for manufacturing thin-walled parts (for example, gas turbine engine blades).

To improve the workability of heat-resistant alloys and reduce negative processes (excessive increase in contact temperature and the occurrence of tensile technological residual stresses) can be achieved by introducing ultrasonic vibrations (UV) into the cutting zone, which facilitate plastic deformations and reduce the coefficient of friction. To assess the possibility of increasing the efficiency of processing a heat-resistant alloy by applying a UV, an experimental research method was developed and an experimental setup was made for rough turning operations (Fig. 1). This setup allows you to conduct a series of experiments that establish the effect of ultrasound on the occurrence of technological residual stresses (TRS), phase transformations (PT), components of cutting forces, contact temperature and help determine further directions of research in this area. For this purpose, in the process of research, X-ray measuring complexes "RIKOR-4" (evaluation of TRS of type I and II), RIKOR-7 (evaluation of PT), device "Siton-ARM" (evaluation of TRS of type III), universal dynamometer UDM-600, TemPro pyrometer -1200/1600/2200, etc. are used (fig. 2-4).

It is well known that ultrasonic vibrations imparted to the cutting tool can have a significant impact on the main components of the cutting force: the alternating stresses created by them accelerate the movement and the formation of dislocations, causing plastic deformation at lower stresses, and cyclic movements of the contact surfaces cause periodic 
rotation of the friction force vectors on the working edges of the tool, significantly reducing the resistance to the immediate flow of chips and facilitates the process of chips formation.

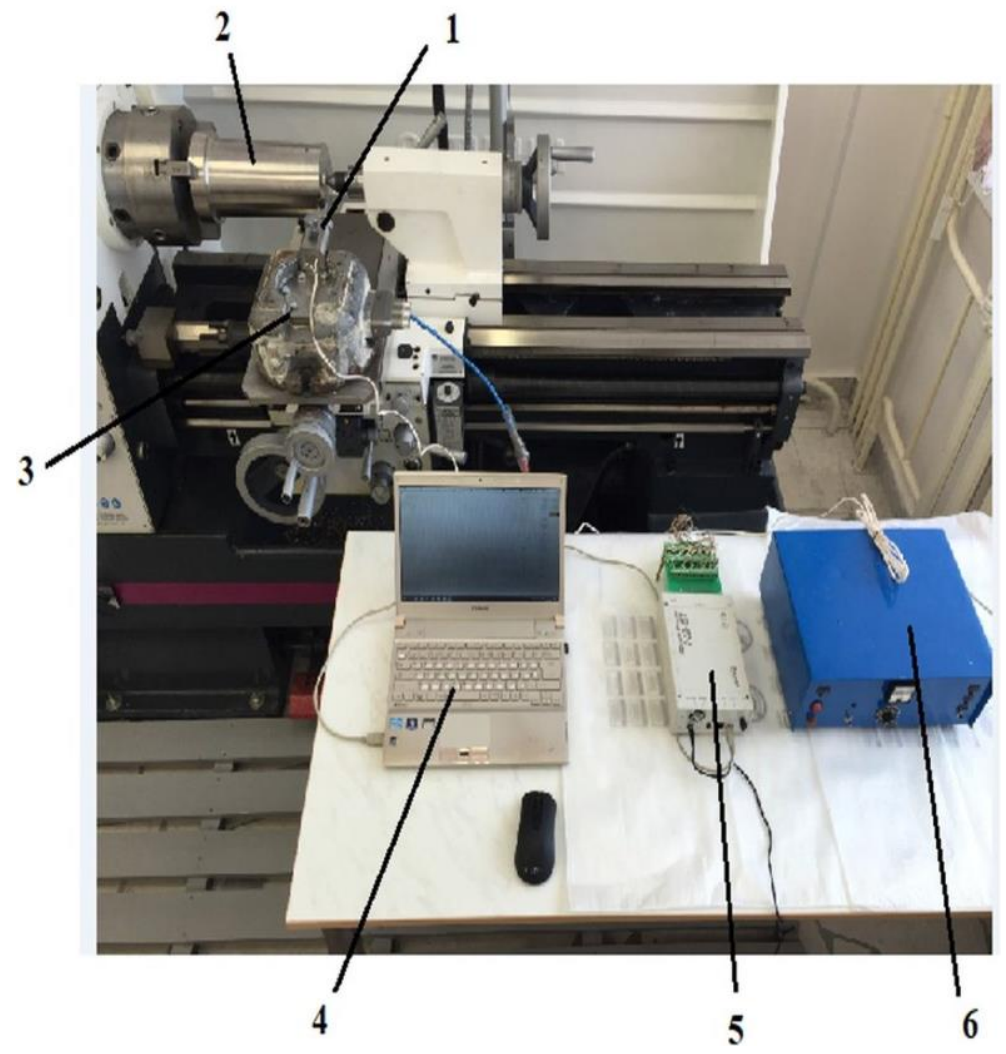

Fig.1. Measuring and recording instruments of an experimental setup for measuring forces and torques: 1-cutter with mineral ceramic plates 2-billet 3-dynamometer UDM-600. 4- computer. 5analog-to-digital converter 6 - ultrasonic generator

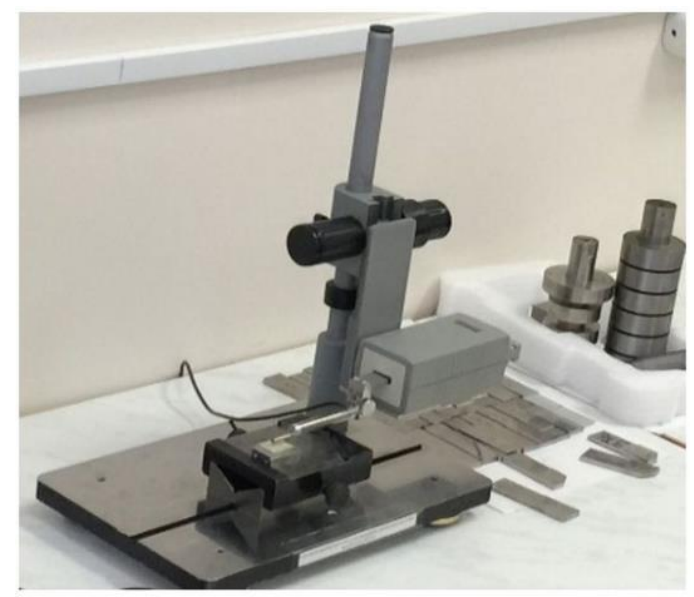

Fig.2. Profilometer - profilograph mod. 170622 plant "Caliber", type II, degree of accuracy 2. 


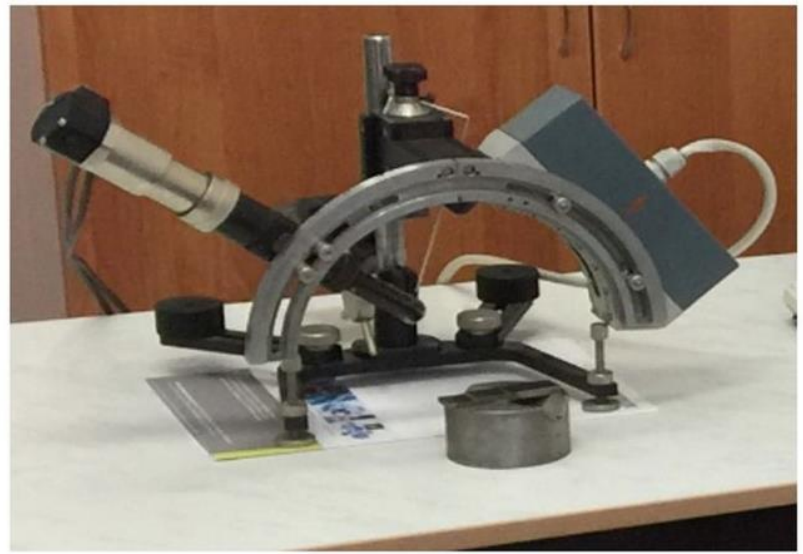

Fig.3. X-ray measuring complex for the assessment of phase changes Rikor-7

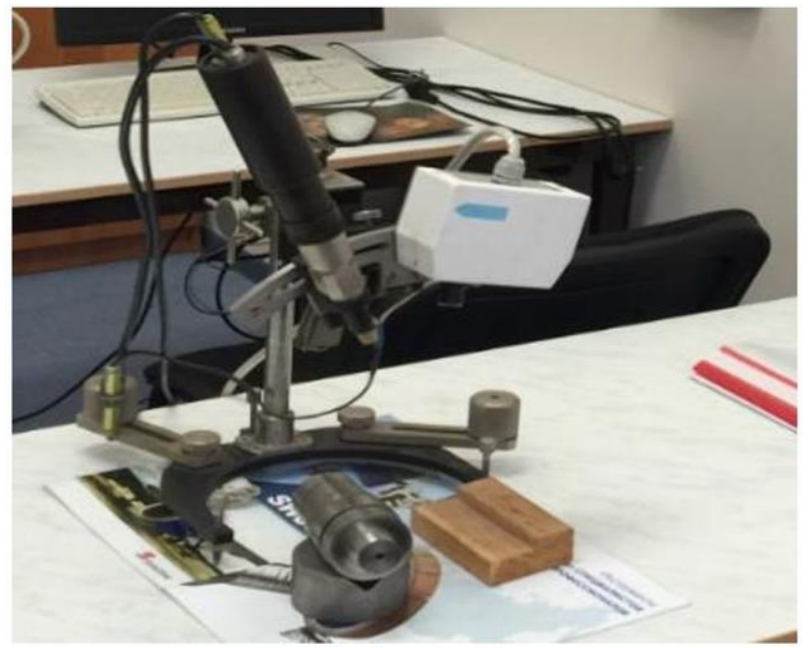

Fig.4. X-ray measuring complex for estimating residual stresses of the first and second types of Ricor-4

Based on the analysis of the literature devoted to the introduction of the energy of ultrasonic vibrations into the treatment area, it can be assumed that ultrasound will have a positive effect on the shaping of parts made of high-temperature alloys $[2,4,7,8,10]$.

\section{The experiments}

Experimental studies were carried out with turning round RNGN120400HRSA round mineral ceramic plates with billets from a heat-resistant alloy HN45MVTUBR (analogue of the alloy Inconel 718) on a Quantum Opti D420x1000 DPA turning machine. In the first series, billet processing was carried out without introducing the energy of ultrasonic vibrations into the shaping zone, in the second, ultrasonic vibration from a ultrasonic generator, frequency $\mathrm{f}=18.6 \mathrm{kHz}$ and amplitude $\mathrm{A}=10 \mu \mathrm{m}$, was applied to the cutting tool. In both series the elements of the cutting mode were used, they are presented in table 1.

Table1. Elements of the mode of turning of billets from heat-resistant alloy 


\begin{tabular}{|c|c|c|c|c|}
\hline $\begin{array}{l}\text { Element } \\
\text { Mode }\end{array}$ & $t, m m$ & $S, m m / r$ & $V, m / m i n$ & $n, r / m i n$ \\
\hline Roughing & 1.5 & 0.1 & 600 & 1740 \\
\hline Finishing & 0.5 & 0.05 & 120 & 350 \\
\hline
\end{tabular}

As can be seen from the analysis of the received data of the preliminary pilot studies, ultrasound vibrations reduces the cutting force components on $20-25 \%$ at roughly and 26$32 \%$ for fine, high-altitude roughness parameters reduced by $18-20 \%$. Significant differences in the qualitative changes of the phase composition of the surface layer of processed billets was found. The detailed results of the research are analyzed.

\section{Conclusions}

Introduction to cutting zone of heat resisting alloys power tools mineral and ceramic fluctuations have a beneficial influence processing performance and the quality of the surface layer of the manufactured parts.

The studies were performed using the funds of the RFBR grant 18-47-730005

\section{References}

1. N.I. Reznikova, Cutting heat-resistant, high-strength and titanium alloys (Mashinostroenie, Moscow, 1972)

2. V.N. Poduraev, Cutting of hard-to-cut materials (Higher School, Moscow, 1974)

3. A.V. Khramov, M.G. Gorshkov, E.S. Kiselev, Vestnik RGATU named after P.A. Solovyov, 2, 219 (2017)

4. E.S. Kiselev, O.V. Blagovsky, Controlling the formation of residual stresses in the manufacture of critical parts: Monography (Lan publishing house, SPb., 2018)

5. P. Deepa Ganesh, International Journal of Mechanical Engineering and Research, 5:1, $53(2015)$

6. Fang and Wu, Journal of material processing technology, 209, 4385 (2009)

7. D. Kumabe, Vibration cutting (Mashinostroenie, Moscow,1985)

8. E.S. Kiselev, Intensification of machining processes using the energy of an ultrasonic field(publishing (UISTU, 2003)

9. M.P. Kozochkin, N.W. Solis, Bulletin RUDN, 2, 16 (2009)

10. E.S. Kiselev, V.N. Kovalnogov, Machining of blanks under conditions critical-mass transfer. Selected works of the Russian school on Science and technology (RAN, Moscow, 2008) 